\title{
Produção de alimentos por agricultores familiares em Vila Bela da Santíssima Trindade (MT), Amazônia Legal
}

\begin{abstract}
As produções familiares têm possibilitado a geração de segurança e soberania alimentar para as comunidades rurais, ao proporcionarem eficiência produtiva energética e ecológica, por meio do adequado manejo do ambiente. Objetivou-se investigar os produtos agrícolas alimentícios que fazem parte do sistema produtivo dos agricultores familiares do Assentamento Seringal e suas respectivas formas de comercialização. Foram entrevistados 86 agricultores familiares vinculados a Associação de Produtores de Látex de Vila Bela da Santíssima Trindade/MT. Os dados foram tabulados em planilha eletrônica e sistematizados por meio das estatísticas de frequência absoluta e relativa. Dos entrevistados $69,01 \%$ é do gênero masculino, sendo o cargo de chefia assumido pelas mulheres apenas quando são as únicas responsáveis pela reprodução familiar. Dentre as diversas culturas produzidas a mandioca é a que aparece com maior frequência (26,76\%). Quanto a produção pecuária, a criação de frango caipira é a atividade de maior relevância, seguida pela de suínos e gado leiteiro. Os produtos são destinados ao autoconsumo familiar e há comercialização do excedente. Geralmente a comercialização é realizada diretamente com o consumidor, entretanto há frequência relativamente alta com atravessadores, com redução de até $40 \%$ no valor pago, se comparado com a venda direta ao consumidor. Com exceção do extrativismo de látex, as demais atividades agrícolas são desenvolvidas na informalidade. Concluiu-se que as principais atividades agropecuárias desenvolvidas nas unidades produtivas do Assentamento Seringal estão ligadas a produção para autoconsumo, com exceção da seringueira, cujo látex é vendido formalmente por uma associação específica, enquanto que para os demais produtos, quando ocorre, é realizado diretamente ao consumidor, cujo produto possui valor agregado ou por intermediários (atravessadores), havendo redução no valor de comercialização.
\end{abstract}

Palavras-chave: Soberania Alimentar; Associações de Produtores; Comercialização do Excedente.

\section{Food production by family farming in the municipality Vila Bela da Santíssima Trindade (MT), Legal Amazon}

\begin{abstract}
Family farming allowed food security and self-sufficiency for rural communities, productive, energetic and ecologic efficiency by appropriate environmental management. The objective of this study was to investigate the food products which are part of the productive system from family farmers of the Seringal Settlement and their respective forms of commercialization. Eighty six farmers were interviewed that are linked to the Association of Latex Producers from Vila Bela da Santíssima Trindade / Mato Grosso State. The data were tabulated in a spreadsheet and systematized by absolute and relative frequency statistics. From the interviewees, $69.01 \%$ were male, and female managers assumed responsibility only when they were the sole ones responsible for family reproduction. Among the several crops produced cassava is the one appearing most frequently $(26.76 \%)$. As far as livestock production is concerned, chicken raise is the most important activity, followed by pigs and dairy cattle. The products are intended for family consumption and the surplus is sold. Usually the commercialization is carried out directly with the consumer, however there is a relatively high frequency of cross-sellers, when there is a reduction of up to $40 \%$ in the amount paid, when compared to the direct sale to the consumer. Except for the latex extraction, the other agricultural activities are developed in informality. It was concluded that the main agricultural activities done in the Seringal Settlement units are linked to the production for self-consumption, except for rubber tree, whose latex is sold formally by a specific association, while for other products, when available, sales of value added products are made directly to the consumer. These products are also sold by intermediaries (middlemen), with a decrease on the value of commercialization.

Keywords: Food Sovereignty; Producer Associations; Trade Surplus.
\end{abstract}

Topic: Química Agrícola e Ambiental

Reviewed anonymously in the process of blind peer.

Keller Regina Soares

Universidade do Estado de Mato Grosso, Brasil

http://lattes.cnpq.br/4202337628291300

kelleragronomia@hotmail.com

Esvanio Edipo da Silva Ferreira

Universidade Federal de Mato Grosso, Brasil

http://lattes.cnpq.br/8821951727659938

esvanioedipo@hotmail.com

\section{Santino Seabra Junior}

Universidade Federal de Mato Grosso, Brasil

http://lattes.cnpq.br/4990974747534079

santinoseabra@unemat.br

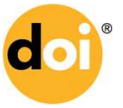

DOI: 10.6008/SPC2179-6858.2017.001.0004
Received: 20/04/2016

Approved: 22/05/2016

\author{
Sandra Mara Alves da Silva Neves \\ Universidade Federal de Mato Grosso, Brasi \\ http://lattes.cnpq.br/6430066425008976 \\ ssneves@unemat.br \\ Leandro Batista da Silva \\ Universidade do Estado de Mato Grosso, Brasil \\ http://lattes.cnpq.br/2562361584173993 \\ agrosilva.mt@gmail.com
}

Referencing this:

SOARES, K. R.; FERREIRA, E. E. S.; SEABRA JUNIOR, S.; NEVES, S. M. A. S.; SILVA, L. B.. Produção de alimentos por agricultores familiares em Vila Bela da Santíssima Trindade (MT), Amazônia Legal. Revista IberoAmericana de Ciências Ambientais, v.8, n.1, p.40-48, 2017. DOI: http://doi.org/10.6008/SPC2179-6858.2017.001.0004 


\section{INTRODUÇÃO}

A agricultura familiar tem sido responsável pela produção dos principais alimentos consumidos pelos brasileiros, em que segundo pesquisas realizadas pelo Núcleo de Estudos Agrários e Desenvolvimento Rural (NEAD): $84 \%$ da mandioca, $67 \%$ do feijão, $54 \%$ do leite, $49 \%$ do milho, $40 \%$ das aves e ovos e $58 \%$ dos suínos (MDA, 2012). Essa categoria social constitui um campo fortemente diverso e importante para o crescimento do Brasil, em termos de acesso e manutenção de recursos, geração de alimentos, acessam a comercialização e capacidade de distribuição de renda (BUAINAIN et al., 2003).

Assim como no país de uma forma geral, em Vila Bela da Santíssima Trindade a agricultura familiar tem atuação importante na produção de alimentos, seja para o autoconsumo dos agricultores familiares e/ou para abastecimento do mercado local. O município apresenta grande diversidade de grupos sociais, como: remanescentes de escravos (quilombolas), grupos indígenas, seringueiros, pequenos agricultores migrantes da região sul e sudeste do país e grandes pecuaristas (LIMA et al., 2015). Os grupos sociais do município atuam hoje na agricultura familiar, que conceitualmente, está diretamente relacionada aos trabalhadores rurais que exploram a terra com a força do trabalho de sua família, visando a sua manutenção (MEDEIROS et al., 1999).

Segundo as diretrizes da Lei da Agricultura familiar no 11.326/2006, os agricultores são classificados como familiares, quando estes indivíduos possuam estabelecimentos rurais com tamanho de 01 a 04 módulos fiscais e que desenvolvam atividades agrícolas através do uso da força de trabalho dos membros da família. Melo (2001), afirma que o que caracteriza o conceito não é o tamanho da propriedade, mas a condição e o uso da força do trabalho.

Os agricultores familiares geralmente adotam sistemas com certa complexidade e biodiversidade, através da utilização de várias espécies vegetais desenvolvidas conjuntamente com a criação de animais usados para o autoconsumo familiar bem como para a geração de renda através da comercialização do excedente da produção (BUAINAIN et al., 2003). Conforme apontamentos dos autores, a diversificação da produção em unidades familiares, tem se configurado em uma estratégia a partir do final da década de 80 , em que as unidades produtivas pouco diversas, eram consideradas vulneráveis frente às crises ecológicas.

Partindo do princípio defendido por Lovisolo (1989), em que uma adversidade não afeta de uma mesma maneira todas as culturas, a utilização de um sistema biodiverso de produção, seja para autoconsumo ou com fundamentos capitalistas, assegura ao agricultor familiar a constância de produção. Além disso, a diversificação pode representar uma economia de recursos, reduzindo assim riscos pela limitação de despesas necessárias e pela não contratação de dívidas (BRUMER, 1994).

Costabeber et al. (2003) evidenciaram que a produção familiar, possibilita a geração de segurança e soberania alimentar para as comunidades rurais, ao proporcionarem eficiência produtiva, energética e ecológica, por meio do adequado manejo do ambiente, indicando que existiam condições de gestar estratégias para a mitigação de problemas inerentes à fome. Altafin (2008), afirma que o apoio produtivo a 
agricultura familiar através de estudos e promoção de tecnologias eficientes de produção é tido como um mecanismo de autoprodução da segurança alimentar.

Nesse sentido, este trabalho tem por objetivo investigar quais os produtos agrícolas alimentícios fazem parte do sistema produtivo dos agricultores familiares do Assentamento Seringal no município de Vila Bela da Santíssima Trindade/MT e suas formas de comercialização.

\section{METODOLOGIA}

\section{Área de estudo}

A pesquisa foi realizada no Assentamento Seringal, localizado no município de Vila Bela da Santíssima Trindade (Figura 1), pertencente à região sudoeste de planejamento do estado de Mato Grosso (MATO GROSSO, 2012). O município está localizado na bacia do Alto Guaporé. Seu território é contemplado por dois biomas: Amazônico (94\%) e Cerrado (6\%). Encontra-se na região de transição entre os domínios morfoclimáticos Amazônico e do Cerrado (AB'SABER, 1967). A população em 2010 era de 14.493 habitantes, sendo que destes 5.166 moravam na cidade e 9.327 no campo (IBGE, 2016). O índice de desenvolvimento humano municipal é de 0,645 (PNUD, 2010).

O Assentamento Seringal foi criado em 18 de abril de 1997 e possui 242 famílias assentadas, sendo que destas 86 fazem parte da Associação de Produtores de Látex (APROLATEX), que possui duas unidades de produção, a primeira, o lote de assentamento com 13,05 ha e o lote de concessão de uso do seringal com 5,45 ha. A área do seringal existia antes da implantação do assentamento, sendo uma área de plantio.

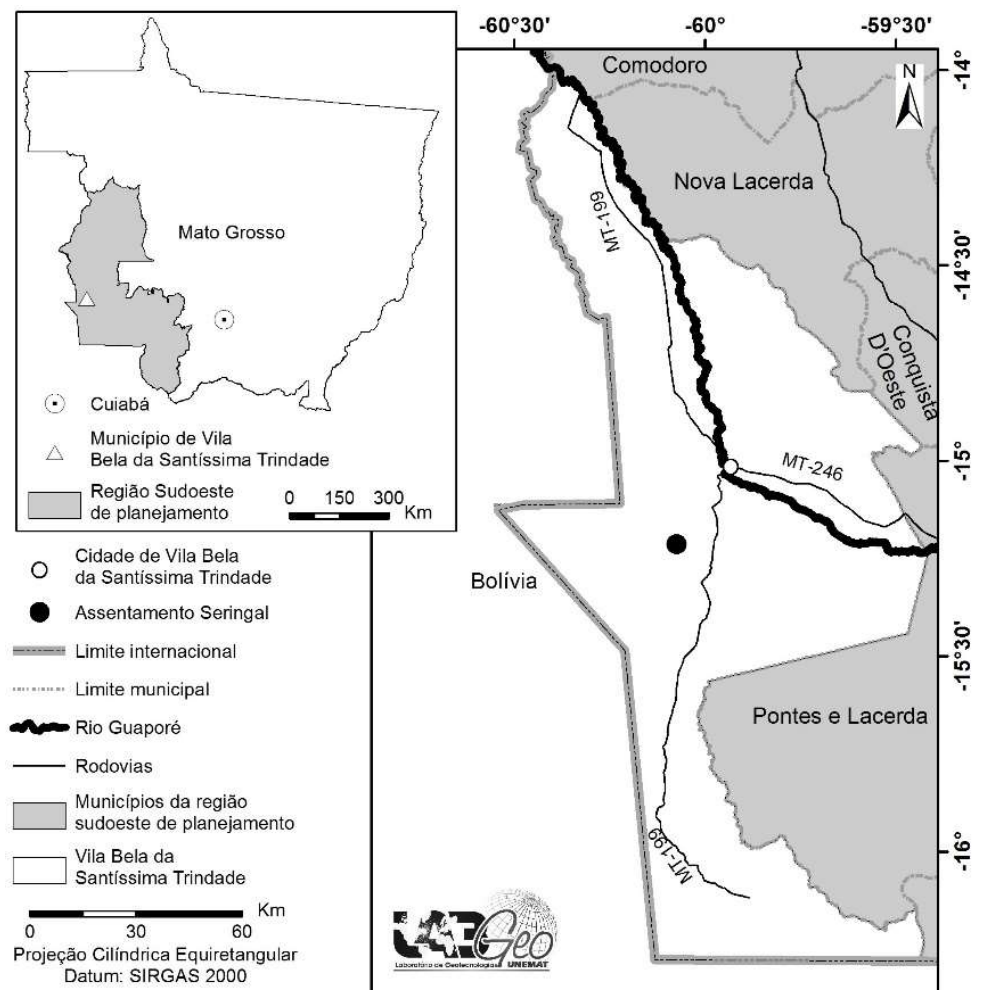

Figura 1: Assentamento Seringal localizado em Vila Bela da Santíssima Trindade/MT no contexto regional. Fonte: LabGeo UNEMAT (2016). 


\section{Procedimentos Metodológicos}

A investigação foi realizada com 86 agricultores familiares do Projeto de assentamento de Seringal, no período de outubro de 2015 e janeiro de 2016. Para a pesquisa, adotou-se a metodologia quantiqualitativa, considerando o sujeito do estudo como "gente, em determinada condição social, pertencente a determinado grupo social ou classe com suas crenças, valores e significados" (MINAYO, 2000).

Para a seleção dos agricultores que fariam parte da pesquisa foi definido que estes deveriam ser os responsáveis pela unidade produtiva, que geralmente eram pessoas de ambos os sexos com tempo de moradia na comunidade acima de 10 anos e que estivessem obrigatoriamente associados à APROLATEX. Dentro dessas exigências, participaram dessa pesquisa todos os agricultores familiares associados, totalizando em 86 entrevistas.

Para a execução das entrevistas foi utilizado o formulário semiestruturado, contendo 80 questões, que abrangiam as temáticas social, econômica e produtiva. As entrevistas foram realizadas na unidade produtiva dos agricultores, pois segundo Duarte (2004), esta transmite ao entrevistado a sensação de tranquilidade e liberdade para a expressão das suas ideias e vivências. Além das entrevistas, foi realizado passeio dirigido (turnê guiada) nas unidades produtivas com a finalidade de se observar a paisagem local bem como os sistemas de produção existentes no assentamento. Segundo Albuquerque e Lucena (2004), o método de passeio dirigido, apresenta como principal característica o uso de estímulos visuais, com o objetivo de conseguir a maior quantidade de informações dessas unidades de produção.

A metodologia do passeio dirigido, também denominada como turnê guiada ou informante de campo, consiste de uma técnica de entrevista em campo, em que o informante aponta as características do sistema de produção. Os passeios dirigidos aconteceram nos locais destinados a produção de alimentos voltados ao autoconsumo dessas famílias.

Para a análise qualitativa, as informações foram classificadas em categorias, que são formadas de acordo com as variadas respostas obtidas na aplicação dos formulários. De acordo com Bardin (2004), a categorização é uma operação de classificação de elementos constitutivos de um conjunto, por diferenciação e, seguidamente, por reagrupamento segundo o gênero (analogia), com os critérios previamente definidos. Assim, a abordagem qualitativa recorre a indicadores não frequenciais susceptíveis de permitir inferências. As categorias são elaboradas e definidas de acordo com o conteúdo das falas dos agricultores da comunidade.

As informações qualitativas e quantitativas obtidas foram tabuladas em planilha eletrônica Excel e, por meio das estatísticas de frequência absoluta $\left(\mathrm{F}_{\mathrm{i}}\right)$, que indica quantas vezes a opção foi selecionada pelos entrevistados, e a frequência relativa $\left(F_{\text {ri }}\right)$, que corresponde à razão entre a frequência absoluta e o número total de observações, expressa em percentual.

\section{RESULTADOS E DISCUSSÃO}

A maioria dos responsáveis pela unidade de produção familiar (UPF) pertence ao gênero masculino $(69,01 \%)$ e as mulheres $(30,99 \%)$ assumem a responsabilidade de chefia da UPF quando são as únicas 
responsáveis pela reprodução familiar, permanecendo no campo, como forma de conseguir o sustento de sua família e por tradição, visto que muitas são de origem rural.

Ribeiro e Oliveira (1999) apontaram que a participação da mulher na agricultura familiar sempre foi subestimada e isso justificaria a maioria dos homens na chefia da unidade produtiva, cabendo à mulher o papel e responsabilidade pela reprodução social do grupo. Assim, de acordo com os autores, as atividades produtivas desenvolvidas por mulheres são atribuídas como parte das tarefas do papel de mãe e esposa, consideradas "ajuda" e "complementares" àquelas desenvolvidas pelos homens. Segundo Melo e Sabbato (2000), as mulheres do meio rural têm a ideologia patriarcal muito mais introjetada em seu comportamento do que as mulheres urbanas.

Após a observação da paisagem local foi possível verificar a existência de diferentes culturas desenvolvidas nas unidades de produção, consideradas pelos agricultores como a principal espécie cultivada. A mandioca é apontada como principal cultura, seguida pela banana (Tabela 1). Além das espécies vegetais alimentícias, o extrativismo de látex tem sido apontado pelos agricultores como uma importante atividade desenvolvida nas UPF's do assentamento. Contudo a atividade é realizada em uma área distinta da área da unidade produtiva, sendo este o fator que fez com que esta cultura tivesse uma baixa frequência de citação. Nesses casos, os agricultores familiares possuem a cultura implantada em sua unidade de produção.

Tabela 1: Caracterização da principal cultura cultivada pelos agricultores familiares do projeto de Assentamento Seringal, em Vila Bela da Santíssima Trindade.

\begin{tabular}{|c|c|c|}
\hline Principal Cultura & $\mathrm{F}_{\mathrm{i}}$ & $\mathrm{F}_{\mathrm{ri}}(\%)$ \\
\hline Mandioca & 19 & 26,76 \\
\hline Seringa & 4 & 5,63 \\
\hline Melancia & 9 & 12,68 \\
\hline Milho & 7 & 9,86 \\
\hline Banana & 15 & 21,13 \\
\hline Abóbora & 2 & 2,81 \\
\hline Alface & 9 & 12,68 \\
\hline Abacaxi & 6 & 8,45 \\
\hline Total & 71 & 100 \\
\hline
\end{tabular}

$F_{i}=$ frequência absoluta; $F_{r i}$ frequência relativa.

Baiardi (1999), afirmou que a agricultura familiar da Bahia apresenta um perfil de produção, visando prioritariamente atender as necessidades da família, e dessa maneira, as culturas mais cultivadas por esses agricultores são a mandioca, feijão, milho e arroz. Como observado por Tsukamoto et al. (2003), em Florianópolis os agricultores familiares geralmente possuem em sua unidade de produção pequenos pomares, feijão, mandioca, abóbora e olerícolas.

Além das culturas elencadas como as principais do sistema produtivo foi possível verificar uma diversidade de culturas plantadas por esses agricultores familiares (Figura 2). A cebolinha aparece em um maior número de estabelecimentos familiares do Assentamento (24,38\%), seguida do maxixe $(15,70 \%)$, quiabo (14,88\%), cana de açúcar (14,05\%) e mandioca (12,81\%), feijão de corda (10,33\%), jiló (9,92\%), banana (9,50\%), pimenta de cheiro (7,85\%), maracujá $(7,02 \%)$, a alface $(7,02 \%)$ e a pimenta bode $(6,20 \%)$, conforme pode ser observado na figura 2. A seringa é a cultura que aparece em menor frequência, sendo citada sua ocorrência em 1,65\%. 
Queiroz (2014), em estudo realizado com agricultores familiares do município de Curvelândia, integrante da região sudoeste de planejamento do estado de Mato Grosso, verificou que as principais culturas presentes em um maior número de estabelecimentos agropecuários foram: quiabo, alface, rúcula, mandioca, cebolinha, pepino e a abóbora.

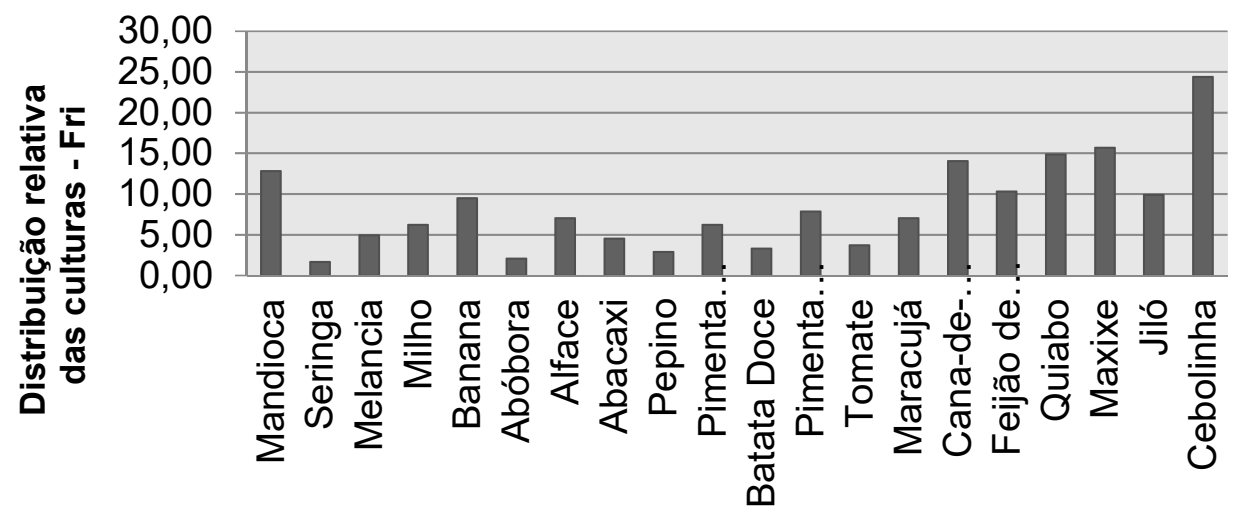

Figura 2: Distribuição relativa das culturas de acordo com o número de estabelecimentos em que são cultivadas, no Assentamento Seringal, Vila Bela da Santíssima Trindade/MT.

A pecuária é desenvolvida em $57,75 \%$ dos lotes do assentamento, sendo que em $24,14 \%$ das unidades de produção existe a criação de gado leiteiro e em 33,79\% a criação de suínos. A produção de frango caipira é a atividade pecuária de maior relevância no Assentamento, considerando o número de lotes em que a atividade é realizada e as unidades de produção (42,07\%).

Carvalho et al. (2010) identificaram em seu estudo sobre agricultura familiar em Uruçuí/PI, que 59\% dos estabelecimentos criavam aves, $25 \%$ bovinos, $11 \%$ suínos, $4 \%$ equinos e $1 \%$ caprinos. Segundo o autor (op. cit.), os rebanhos bovino, suíno, caprino e de aves destinavam-se preponderantemente para o consumo familiar e, apenas quando estritamente necessário, comercializavam parte das cabeças, para suprir necessidades domésticas urgentes.

A destinação dessa produção, para $89,53 \%$ dos agricultores é para o autoconsumo e venda do excedente, enquanto que os demais $(10,47 \%)$ produzem exclusivamente para a comercialização. Entre os agricultores que aderem a prática de autoconsumo, 65\% vendem o excedente. Dessa forma, a produção para autoconsumo faz parte da estratégia de reprodução das famílias rurais, por permitir uma alimentação diversificada e constante. Segundo Maluf et al. (2001), podendo dispor de alguns alimentos produzidos pela família, a renda adquirida com a venda de pequenos excedentes pode fazer frente a outras necessidades, como gastos com saúde, educação, vestuário e habitação.

O autoconsumo desempenha um papel nas formas sociais de produção e trabalho que está relacionado a propiciar a diversificação das estratégias de vivência das famílias. Nesse sentido, o que se quer demonstrar é que a produção de auto provisionamento é a base sobre a qual se assenta, materialmente, grande parte da reprodução social e alimentar do grupo doméstico e o ponto de partida para que as unidades de produção consigam diversificar as suas estratégias de vivência (GAZOLLA, 2006). 
A comercialização do látex é realizada através da APROLATEX, sendo por isso considerada a única atividade comercializada formalmente por esses agricultores familiares, tendo em vistas que os demais produtos oriundos das unidades de produção do assentamento Seringal é realizada na sua maior parte diretamente com os consumidores, conforme pode ser observado na tabela 2. Nessa modalidade as vendas podem ser realizadas na própria unidade de produção (35\%) e em pontos de vendas distribuídos no município.

Tabela 2: Formas de comercialização realizadas pelos agricultores familiares do projeto de Assentamento Seringal, em Vila Bela da Santíssima Trindade/MT.

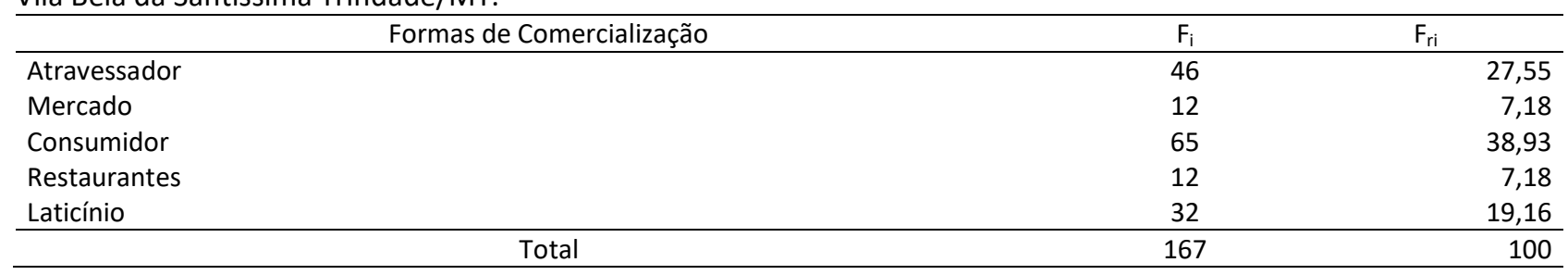

$F_{i=}$ frequência absoluta; $F_{r i}$ frequência relativa

A frequência relativamente alta de comercialização realizada com atravessadores chama a atenção neste caso (Tabela 2), tendo em vista que os agricultores vendem seus produtos com uma redução de até $40 \%$ do valor, quando comparado com a venda direta ao consumidor. Apesar da desvalorização do produto essa prática é bem comum, principalmente com a entrega de leite e olerícolas, prática essa que pode ser atribuída às dificuldades de escoamento da produção. A falta de estrutura e planejamento da produção aliada as condições precárias da estrada que dá acesso ao assentamento são as principais responsáveis pelas dificuldades de escoar os produtos, tendo em vista que esses agricultores não possuem meio de transporte adequado e nem produzem individualmente uma quantidade que compense o transporte. Dessa maneira, a organização desses agricultores em associação para essas atividades produtivas, tem importância relevante, pois seria uma das alternativas para reduzir a presença dos atravessadores durante o processo de comercialização de seus produtos.

Segundo Marafon (2006), agricultores familiares na grande maioria das vezes, ficam a mercê dos atravessadores que controlam o processo de comercialização da produção. Com isso acabam tendo uma baixa remuneração por suas atividades agrícolas.

Apesar dos agricultores fazerem parte de uma associação, essa defende os interesses apenas da atividade de extrativismo de látex, enquanto que as demais atividades agrícolas são desenvolvidas na informalidade. Apesar da importância da produção agropecuária para a alimentação dessas famílias bem como para a geração de renda, os agricultores tem enfrentado problemas para formalizar suas propriedades, principalmente pela dificuldade de produção em escala suficiente para atender o mercado aliado aos altos custos tributários para a legalização de seus empreendimentos. De acordo com Estevam et al (2012), as dificuldades que os agricultores familiares encontram para se inserir no mercado formal são muitas, além das barreiras tributárias, sanitárias e de escala de produção. Dessa maneira, os agricultores optam por realizar contratos informais, principalmente com atravessadores legalizados para a comercialização destes produtos. 
"A informalidade tem limitado o mercado de produtos da agricultura familiar, em que a sobrevivência da agricultura familiar está diretamente ligada à competitividade dos canais de distribuição" (AZEVEDO e FAULIN, 2005, p. 238). Segundo os autores (op. cit.), os contratos informais, baseado na confiança, podem gerar problemas ao agricultor familiar, pois a outra parte pode agir de forma oportunista, utilizando de sua posição privilegiada em relação a informações de mercado.

Uma alternativa para os agricultores familiares não ficarem totalmente a mercê do mercado, seria a comercialização coletiva, através da formação de associações e/ou cooperativas para essa finalidade, pois de acordo com Gehlen (2004), as ações associativas podem otimizar ganhos por meio da compra e venda em comum, da pressão por barganhar melhores preços e facilitar o escoamento dos produtos.

\section{CONCLUSÕES}

Concluiu-se que as principais atividades agropecuárias desenvolvidas nas unidades produtivas do Assentamento Seringal estão ligadas a produção para autoconsumo, com exceção da seringueira, que é uma atividade exclusivamente comercial.

Quanto à comercialização, o látex é vendido formalmente através de uma associação específica para essa atividade, enquanto que para os demais produtos agropecuários, quando ocorre, é realizado de duas formas: diretamente ao consumidor, cujo produto possui valor agregado, e através de intermediários (atravessadores), em que ocorre redução no valor de comercialização dos produtos.

\section{AGRADECIMENTO}

A equipe do projeto de extensão: “Núcleo de extensão em Desenvolvimento Territorial da grande Cáceres: uma estratégia de desenvolvimento sustentável por meio de ações que fortaleçam a produção agroecológica, agroindustrialização, comercialização e a atuação das mulheres" financiado no âmbito do Edital CNPq/MDA/ SPM n $n^{0.11 / 2014 ~-~ A p o i o ~ a ~ i m p l a n t a c ̧ a ̃ o ~ e ~ m a n u t e n c ̧ a ̃ o ~ d e ~ n u ́ c l e o s ~ d e ~ e x t e n s a ̃ o ~ e m ~ d e s e n v o l v i m e n t o ~}$ territorial. À Coordenação de Apoio ao Pessoal de Nível Superior - Capes pela concessão de bolsa de mestrado a autora deste texto.

\section{REFERÊNCIAS}

AB'SÁBER, A. N.. Domínios Morfoclimáticos e províncias fitogeográficas do Brasil. Revista Orientação, n.3, p.45-48, 1967.

ALTAFIN, I.. Reflexões sobre o conceito de agricultura familiar. Brasília: Fav/UnB, 2008.

BAIARDI, A.. Formas de agricultura familiar, à luz dos imperativos de desenvolvimento sustentável e de inserção no mercado internacional. In: CONGRESSO BRASILEIRO DE ECONOMIA E SOCIOLOGIA RURAL, 37. Anais. Foz do Iguaçu: SOBER, 1999.

BARDIN, L.. Análise de conteúdo. 3 ed. Lisboa: Edições 70, 2004.
BRASIL. Lei no 11.326, de 24 de julho de 2006. Estabelece as diretrizes para a formulação da Política Nacional da Agricultura Familiar e Empreendimentos Familiares Rurais. Brasília: DOU, 25 jul. 2006.

BRUMER, A.. Transformações e estratégias produtivas na produção familiar gaúcha. Cadernos de Sociologia, Porto Alegre, v.6, p.98-111, 1994.

BUAINAIN, A. M.; ROMEIRO, A. R.; GUANZIROLI, C. Agricultura familiar e o novo mundo rural. Sociologias, v.5, n.10, p.312-347, 2003.

CARVALHO, M. L. S.; LUCAS, M. R. D. V.; HENRIQUES, P. D.. A multifuncionalidade na agricultura $\mathrm{e}$ as suas valências. Lisboa: Sociedade Portuguesa de Estudos Rurais, 2010. 
COSTABeber, J. A.; CAPORAL, F. R.. Possibilidades e alternativas do desenvolvimento rural sustentável. In: VALE, H.. Agricultura familiar e desenvolvimento rural sustentável no MERCOSUL. Santa Maria: EdUFSM/Pallotti, 2003. p.157194

ESTEVAM, D. O.; LANZARINI, J. J. S.; BUSARELLO, R. J.. Cooperativas Virtuais e o difícil caminho da legalidade: o caso dos Agricultores Familiares da Região do Sul do Estado de Santa Catarina. In: ENCONTRO DA REDE DE ESTUDOS RURAIS, 5. Anais. Belém, 2012.

GAZOLLA, M.. O processo de mercantilização do consumo de alimentos na agricultura familiar. In: SCHNEIDER, S.. A diversidade da agricultura familiar. Porto Alegre: EdUFRGS, 2006. p.32-39

GEHLEN, I.. Políticas públicas e desenvolvimento social rural. São Paulo em perspectiva, v.18, n.2, p.95-103, 2004.

LEITE, S. P.. Autoconsumo y sustentabilidad en la agricultura familiar: una aproximación a la experiencia brasileña. In: BELIK, W.. Políticas de seguridad alimentaria y nutrición en América Latina. São Paulo: Hucitec, 2004. p.123-181

LIMA, A. C.; SILVA, C. J.; VIANA, I. G.; ARRUDA, J. C.; DUTRA, M. M.; SANDER, N. L.; MORATTI, P. R.. Quintal espaço de saberes e de segurança alimentar no Vale do Guaporé, Amazônia Meridional, Mato Grosso. Revista de Estudos Sociais, v.17, n.34, p.139-148, 2015.

LOVISOLO, H.. Terra, trabalho e capital: produção familiar e acumulação. Campinas: EdUNICAMP, 1989.

MALUF, R. S; REIS, M. C.. Manifestação de Insegurança Alimentar, Roteiro de Aula, Curso Conceitos e Princípios em Segurança Alimentar. REDECAPA, 2005.

MALUF, R.; MENEZES, F.; MARQUES, S.. Caderno Segurança Alimentar. Montpelier: Fondation Charles Léopold Mayer pour le Progrès de l'Homme, Red Agriculturas Campesinas, Sociedades y Globalización (APM), 2001.

MARAFON, G. J.. Agricultura familiar, pluriatividade e turismo: reflexões a partir do território fluminense. CampoTerritório: Revista de Geografia Agrária, v.1, n.1 p.17-40, 2006.

MATO GROSSO. Secretaria de Estado de Planejamento e Coordenação Geral. Plano de Longo Prazo de Mato Grosso: macro-objetivos, metas globais, eixos estratégicos e linhas estruturantes. In: PRADO, J. G. B.; BERTCHIELI, R.; OLIVEIRA,
L. G.. Plano de Longo Prazo de Mato Grosso. Cuiabá: Central de Texto, 2012

MDA. Ministério de Desenvolvimento Agrário. Agricultura Familiar. 2016.

MEDEIROS, L; LEITE, S.. A Formação dos assentamentos rurais no Brasil: Processos Sociais e Políticas Públicas. Porto Alegre; Rio de Janeiro: Ed. Universidade UFRGS; CPDA. 1999.

MELO, H. P.; SABBATO, A.. O feminino no mundo rural: um olhar pela PNAD/IBGE. In: CONGRESSO MUNDIAL DE SOCIOLOGIA RURAL, 10. CONGRESSO BRASILEIRO DE ECONOMIA E SOCIOLOGIA RURAL, 38. Anais. Anais. Brasília: SOBER, 2000

MELO, F. H.. Liberalização comercial e agricultura familiar no Brasil In: Comércio internacional, segurança alimentar e agricultura familiar. Rio de Janeiro: Rebrip; Action Aid Brasil, 2001.

MINAYO, M. C. S.. Pesquisa social: teoria método e criatividade. 16 ed. Petrópolis: Vozes, 2000.

QUEIROZ, R. F. N.. Análise agroclimática do melão na região sudoeste mato-grossense: contribuições para o fortalecimento da agricultura familiar. Dissertação (Mestrado em Ambiente e Sistemas de Produção Agrícola) Universidade do Estado de Mato Grosso, Tangará da Serra, 2014.

RIBEIRO, E. M.; OLIVEIRA, L.. Ocupação e emprego na agropecuária mineira nos anos 90. Revista de Economia Rural, v.9, n.6, p.29-34, 1999.

TSUKAMOTO, R. Y.; ASARI, A, Y.. Assentamentos Rurais e Agricultura familiar: processo de territorialização e perspectiva de autosustentação. Londrina: EDUEL, 2003.

WAGNER, S. A.; MARQUES, F. C.; MENASCHE, R.. Agricultura familiar a mesa. In: MENASCHE, R.. A agricultura familiar à mesa: Saberes e práticas da alimentação no Vale do Taquari. Porto Alegre: EdUFRGS, 2007. p.33-45

WALTER. M. I.. Estimação do ICV em 37 territórios rurais: relatório conjunto da pesquisa de campo das células de acompanhamento e informação. Brasília: IICA/MDA/ SDT, 2011.

ZANETTI, C.; MENASCHE, R.. Segurança alimentar, substantivo feminino: mulheres agricultoras e autoconsumo. In: MENASCHE, R.. A agricultura familiar à mesa: Saberes e práticas da alimentação no Vale do Taquari. Porto Alegre: EdUFRGS, 2007. p.01-08. 